\title{
Comparação da eficiência dos tratamentos físico-químicos de efluente têxtil utilizando sulfato de alumínio, carvão ativado e o processo oxidativo avançado fenton (H2O2)
}

As etapas de lavagem e tingimento dos tecidos resultam em um efluente altamente poluidor, necessitando de tratamento prévio para posterior despejo em corpo hídrico. Há diversos tipos de tratamentos de efluentes, e, com base nisso, a escolha de um tratamento adequado irá depender das características químicas do efluente em questão e o seu grau de toxicidade. Este presente trabalho tem como objetivo avaliar e comparar a eficiência dos processos de tratamento físicoquímicos coagulação-floculação seguido de adsorção e POA usando como resposta os parâmetros cor, turbidez, pH e DQO (demanda química de oxigênio). As amostras utilizadas nos testes foram advindas de uma lavanderia industrial de jeans, sendo o efluente têxtil final. Para os tratamentos, as amostras foram coletadas e não foram realizados nenhum tipo de tratamento prévio. O carvão ativado foi utilizado como adsorvente e sulfato de alumínio como coagulante. Para o tratamento estatístico foram realizados os testes de normalidade de Shapiro-Wilk $(a=0,05)$ para depois serem realizados a regressão linear bivariada, correlação de Pearson e a correlação bivariada de Kendall para posterior análise descritiva. O POA obteve uma melhor resposta frente aos outros tratamentos e os melhores resultados para a diminuição do parâmetro analisado: $\mathrm{DQO}$ (96\%) na quantidade de $\mathrm{Fe}+2 / \mathrm{H} 2 \mathrm{O} 2$ de 0,55 g.

\section{Comparasion of the efficiency of physical and chemical treatments of textile effluent using aluminium sulfate, activated coal and the advanced oxidative process fenton (H2O2)}

\begin{abstract}
The washing and dyeing stages of the tissues result in a highly polluting effluent, requiring prior treatment for subsequent disposal into the water body. There are several types of effluent treatment, and based on this, the choice of an appropriate treatment will depend on the chemical characteristics of the effluent in question and its degree of toxicity. This work aims to evaluate and compare the efficiency of physical-chemical treatment processes coagulation-flocculation followed by adsorption and POA using the parameters color, turbidity, $\mathrm{pH}$ and COD (chemical oxygen demand). The samples used in the tests came from an industrial jeans laundry, being the final textile effluent. For the treatments, the samples were collected and no previous treatment was performed. Activated carbon was used as an adsorbent and aluminum sulfate as a coagulant. For the statistical treatment, Shapiro-Wilk normality tests ( $a=0.05)$ were performed and then bivariate linear regression, Pearson correlation and Kendall bivariate correlation were performed for further descriptive analysis. The POA obtained a better response compared to other treatments and the best results for the reduction of the analyzed parameter: $\mathrm{COD}(96 \%)$ in the amount of $\mathrm{Fe}+2 / \mathrm{H} 2 \mathrm{O} 2 \mathrm{of} 0.55 \mathrm{~g}$.
\end{abstract}

Keywords: Environmental pollution; Textile effluent; Physical-chemical treatment; Oxidative-advanced process.

Topic: Engenharia Ambiental

Reviewed anonymously in the process of blind peer.
Received: 06/04/2021

Approved: 27/04/2021
Shara Sonally Oliveira de Sousa (D)

Universidade Federal Rural de Pernambuco, Brasil http://lattes.cnpq.br/6478374701154386

http://orcid.org/0000-0003-1024-1441 sharaoliveirassos@gmail.com

Gleyton Lopez Barboza Lacerda (iD Universidade Federal Rural de Pernambuco, Brasil http://lattes.cnpq.br/0941837243510458 http://orcid.org/0000-0002-1645-4387 gleytonlb@gmail.com

Milla Gomes Albuquerque

Universidade Federal Rural de Pernambuco, Brasil http://lattes.cnpq.br/9272766444917783 http://orcid.org/0000-0001-5782-9125 millagomes0410@gmail.com

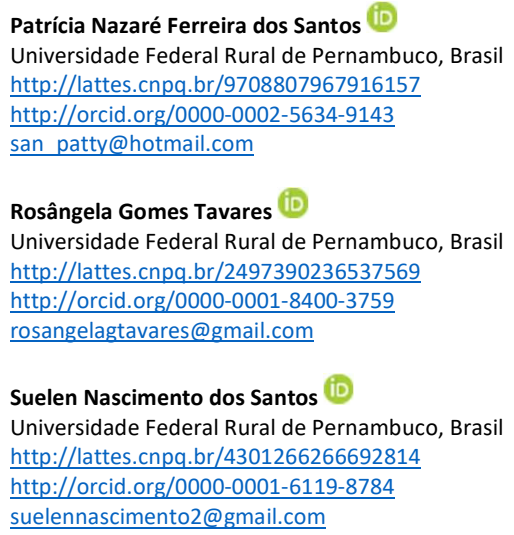

Patrícia Nazaré Ferreira dos Santos (iD Universidade Federal Rural de Pernambuco, Brasil http://lattes.cnpq.br/9708807967916157 http://orcid.org/0000-0002-5634-9143 san_patty@hotmail.com

Rosângela Gomes Tavares (iD

Universidade Federal Rural de Pernambuco, Brasil http://lattes.cnpq.br/2497390236537569 http://orcid.org/0000-0001-8400-3759 rosangelagtavares@gmail.com

Suelen Nascimento dos Santos (iD

Universidade Federal Rural de Pernambuco, Brasil http://lattes.cnpq.br/4301266266692814 http://orcid.org/0000-0001-6119-8784 suelennascimento2@gmail.com

Viviane Borges Dias (iD)

Universidade Federal Rural de Pernambuco, Brasil http://lattes.cnpq.br/3422303365833115 http://orcid.org/0000-0002-9151-3340 borgesdias.eng@gmail.com

Referencing this:

SOUSA, S. S. O.; LACERDA, G. L. B.; ALBUQUERQUE, M. G.; SANTOS, P. N. F.; TAVARES, R. G.; SANTOS, S. N.; DIAS, V. B.. Comparação da eficiência dos tratamentos físico-químicos de efluente têxtil utilizando sulfato de alumínio, carvão ativado e o processo oxidativo avançado fenton (H2O2). Revista Ibero Americana de Ciências Ambientais, v.12, n.4, p.412-425, 2021. DOI: http://doi.org/10.6008/CBPC2179$\underline{6858.2021 .004 .0032}$ 
Comparação da eficiência dos tratamentos físico-químicos de efluente têxtil utilizando sulfato de alumínio, carvão ativado e o processo oxidativo avançado fenton (H2O2)

SOUSA, S. S. O.; LACERDA, G. L. B.; ALBUQUERQUE, M. G.; SANTOS, P. N. F.; TAVARES, R. G.; SANTOS, S. N.; DIAS, V. B.

\section{INTRODUÇÃO}

Desde a Revolução Industrial, iniciada no século XVIII, a humanidade tem vivenciado inúmeras modificações no modo de vida das pessoas. A utilização dos recursos naturais para satisfação das necessidades humanas tem provocado profundas mudanças na dinâmica dos sistemas naturais e grandes impactos ambientais. Sendo assim, é de fundamental importância tratar os efluentes produzidos por essas atividades, pois os prejuízos causados por eles desencadeiam desordem na qualidade ambiental e na saúde pública. É um compromisso ambiental o tratamento de efluentes, visto os distúrbios e danos potenciais que eles podem causar devido à gama de componentes químicos peculiares e prejudiciais que cada efluente contém, observando, também, a geração de cada efluente, devendo ser controlada (BELTRAME et al., 2016).

A escolha do processo de tratamento adequado para cada tipo de efluente é de fundamental importância para se atingir eficiência no tratamento, sendo fundamental examinar um número considerável de variáveis intrínsecas dos tratamentos de esgoto para obter-se o melhor tipo de tratamento (VON SPERLING, 2014; MOLINOS-SENANTE et al., 2015). O tipo de tratamento a ser escolhido vai depender das características do efluente a ser tratado, de acordo com a carga poluidora e a toxicidade deste efluente que pode ser reduzida. A escolha também será feita a depender da metodologia que garantam a necessária eficiência na degradação de poluentes conforme destinação da água (QUEIROZ et al., 2019).

As indústrias têxteis utilizam grandes quantidades de água, corantes, principalmente o índigo, além de diferentes sais, surfactantes, óleos minerais, metais pesados e amido que se desprendem do tecido denim no processo de lavagem (HASSAN et al., 2009). Assim, estes efluentes apresentam cor elevada e também valores extremos de $\mathrm{pH}, \mathrm{DQO}$ e DBO com baixa biodegradabilidade. Além disso, um dos principais resíduos gerados após o tratamento destes efluentes é o lodo, que contém metais pesados, este possui uma relação direta entre a qualidade do efluente e as características do resíduo sólido (QUEIROZ et al., 2016).

A grande quantidade de corantes reativos com pouca degradabilidade é o que gera o problema da cor intensa nos efluentes têxteis sendo assim de difícil eliminação pelos processos biológico e físico-químicos. O tratamento biológico aeróbio é bastante utilizado em efluentes têxteis, devido sua boa capacidade de remoção de carga orgânica e por ser um processo seguro. Através de um processo secundário biológico, as substâncias orgânicas podem ser removidas, mas a cor é reduzida através de métodos físico-químicos (CUNHA et al., 2019). Os processos oxidativos avançados (POA) tem recebido destaque no tratamento e prétratamento de compostos de difícil biodegradabilidade em águas residuárias em indústria têxtil (LUTOSA et al., 2013).

Os processos físico-químicos como a coagulação/floculação e processos de oxidação avançada (POA) são estratégias utilizadas para uma melhor eficiência no tratamento da vinhaça. A coagulação ocorre a desestabilização das partículas coloidais por meio de eletrólitos, e em seguida dá-se a agregação dos coloides desestabilizados (FRANCO et al., 2017). Os Processos Oxidativos Avançados (POA) são técnicas de degradação de poluentes, capazes de alterar a estrutura dos poluentes através da geração de radicais hidroxila $(\mathrm{OH} \bullet)$. Estes processos têm sido aplicados com êxito para a remoção ou a degradação de poluentes recalcitrantes 
(ARAÚJO et al., 2016). Já a adsorção, que é um processo de transferência de massa que ocorre de uma fase fluida para fase sólida, em que determinados sólidos são capazes de concentrar outras substâncias na sua superfície (STOPPE et al., 2019).

O parâmetro DQO indica o grau de poluição orgânica biodegradável, cuja presença promove um grande consumo de oxigênio, que venha a inviabilizar a existência de seres aquáticos no corpo d'água (LATIF et al., 2015). Com o intuito de reduzir o potencial poluidor de determinado efluente com elevada carga orgânica pode-se usar os tratamentos de coagulação/floculação, adsorção, POA ou ainda a junção desses associados ou não a tratamentos biológicos.

O objetivo deste trabalho foi avaliar e comparar a eficiência dos tratamentos físico-químicos coagulação-floculação com sulfato de alumínio, e adsorção com carvão ativado, e Processo Oxidativo Avançado ( $P O A$ ) Fenton $\mathrm{H}_{2} \mathrm{O}_{2}$, através dos parâmetros turbidez, pH e DQO (demanda química de oxigênio) do efluente têxtil.

\section{MATERIAIS E MÉTODOS}

\section{Amostragem}

As amostras utilizadas nos testes foram provenientes de uma lavanderia industrial de produção de jeans na região Agreste do Pernambuco. Foram realizadas 5 coletas no ponto de saída do efluente, sem nenhum tipo de tratamento prévio. A partir das 5 coletas foi obtida uma amostra composta, que foi caracterizada quanto ao $\mathrm{pH}$, turbidez e DQO, segundo os métodos estabelecidos no Standard Methods for the Examination of Water and Wastewater, conforme a tabela 1.

Tabela 1: Métodos utilizados para análises físico-químicos.

\begin{tabular}{l|l}
\hline Parâmetros & Método \\
\hline $\mathrm{pH}$ & Método Potenciométrico - 4500B \\
\hline Turbidez & Método Nefelométrico - 2130 B \\
\hline DQO & Método Espectrofotométrico - 5220D \\
\hline
\end{tabular}

\section{Ensaios de coagulação/floculação}

Os experimentos de coagulação/floculação foram realizados em equipamento Jar - test para seis amostras, marca MILAN modelo JT303M, segundo a metodologia adotada por Cunha et al. (2019). O coagulante utilizado foi o sulfato de alumínio comercial, fornecido pela Companhia Pernambucana de Saneamento - COMPESA. O teste consistiu na adição de diferentes dosagens de coagulantes em béqueres de prova contendo $1000 \mathrm{~mL}$ do efluente têxtil. As alíquotas de coagulantes/floculantes, soluções com concentração pré-determinadas preparadas a partir de uma solução a $1 \%$ obtida da diluição do produto comercial a 50\%, foram adicionadas diretamente à amostra, durante o tempo de mistura rápida (TMR) de 10 segundos a 100 RPM, para desestabilizar a suspensão. Seguiu-se após o TMR o tempo de mistura lenta (TML) de 30 minutos a 35 RPM para facilitar a floculação. Após esse tempo seguiu-se o tempo de sedimentação (SED) de 20 minutos, em seguida foram retiradas amostras do sobrenadante e realizadas, em triplicata, as determinações de pH, DQO e turbidez (Figura 1). 


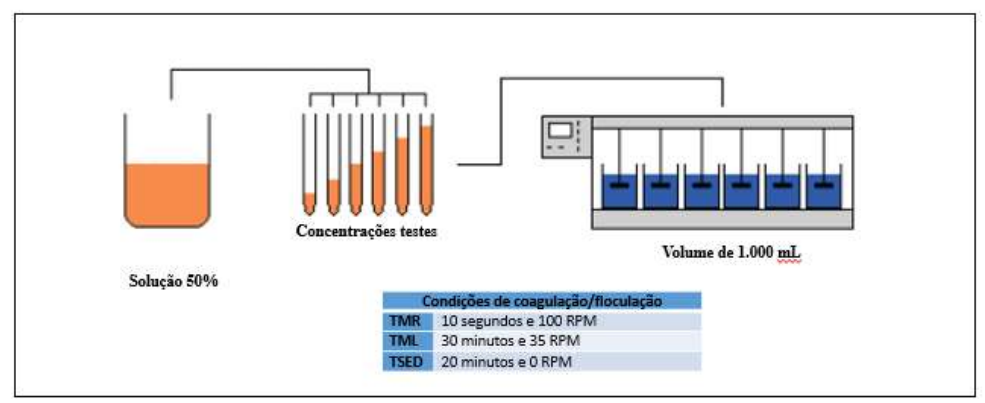

Figura 1: Esquema do ensaio de coagulação/floculação

As concentrações dos coagulantes foram determinadas por variação da dosagem de coagulante em condições reais. $O$ intervalo de estudo das concentrações de coagulantes foram de $0,2-0,6 \mathrm{mg} / \mathrm{L}$, baseado na relação dosagem de sulfato de alumínio e turbidez. Logo ficou estabelecido 10 tratamentos de coagulação/floculação, conforme a Tabela 2.

Tabela 2: Tratamentos de Coagulação/Floculação.

\begin{tabular}{l|l}
\hline Tratamento & Dosagem de coagulante $\left(\mathbf{A l}_{\mathbf{2}}\left(\mathbf{S O}_{\mathbf{4}} \mathbf{~} \mathbf{2}_{\mathbf{2}}\right) \mathbf{~} \mathbf{g} / \mathbf{L}\right.$ \\
\hline T1CF & 15 \\
\hline T2CF & 20 \\
\hline T3CF & 25 \\
\hline T4CF & 30 \\
\hline T5CF & 35 \\
\hline T6CF & 40 \\
\hline T7CF & 45 \\
\hline T8CF & 50 \\
\hline T9CF & 55 \\
\hline T10CF & 60 \\
\hline
\end{tabular}

\section{Ensaios de adsorção}

\section{Determinação do Ponto de Carga Zero (PCZ)}

Para a determinação do ponto de carga zero foi-se pesado aproximadamente $50 \mathrm{mg}$ dos adsorventes e adicionado aos mesmos $50 \mathrm{~mL}$ de solução aquosa com valores de $\mathrm{pH}$ variando de 1,0 a $12 \mathrm{em}$ Erlenmeyer de $250 \mathrm{~mL}$, os quais foram transferidos para uma mesa agitadora sob agitação de 100 rpm, por 24 horas. Depois de 24 horas de equilíbrio mediu-se o pH final com o auxílio de um pHmetro de bancada calibrado com soluções padrão de $\mathrm{pH} 4$ e de $\mathrm{pH}$ 7. Em seguida produziu-se os gráficos de $\mathrm{pH}$ inicial versus $\mathrm{pH}$ final para cada adsorvente, sendo que o PCZ de cada amostra foi obtido na faixa onde se observou o efeito tampão, ou seja, onde o pH não variou (independentemente do pH inicial). Desta forma, foi feito uma média aritmética dos valores de $\mathrm{pH}$ final que tendem aos mesmos valores para a determinação do PCZ.

\section{Teste de Adsorção}

O adsorvente utilizado foi o carvão ativado de origem comercial em pó com gravimetria de 50-100 $\mu \mathrm{m}$ de diâmetro. Os tratamentos foram realizados em triplicata, adotando a variação da massa do adsorvente (gramas) e o pH do efluente, conforme Tabela 3. A variação do pH foi estabelecida em função do PCZ, sendo o mesmo o ponto central e um pH ácido $(5,5)$ e outro alcalino $(8,5)$. 
Tabela 3: Planejamento massa do adsorvente e $\mathrm{pH}$ do efluente.

\begin{tabular}{l|l|l|l|l}
\hline Tratamento & Massa (g/L) & pH & \multicolumn{2}{l}{} \\
\hline T1 AD & 0,2 & 5,5 & 7,2 & 8,5 \\
\hline T2AD & 0,4 & 5,5 & 7,2 & 8,5 \\
\hline T3 AD & 0,8 & 5,5 & 7,2 & 8,5 \\
\hline T4 AD & 1,0 & 5,5 & 7,2 & 8,5 \\
\hline T5 AD & 2,0 & 5,5 & 7,2 & 8,5 \\
\hline T6 AD & 4,0 & 5,5 & 7,2 & 8,5 \\
\hline T7 AD & 6,0 & 5,5 & 7,2 & 8,5 \\
\hline
\end{tabular}

Os tratamentos foram realizados com $50 \mathrm{ml}$ do adsorvato o efluente têxtil e a massa estabelecida do adsorvente, o carvão ativado, em mesa agitadora, marca QUIMIS, na velocidade de 200 rpm por 60 minutos. Após o período de agitação as amostras foram filtradas papel de filtro quantitativo, faixa preta com $28 \mu \mathrm{m}$. Em seguida foram realizadas análises de $\mathrm{pH}$, turbidez e DQO.

\section{Teste de Oxidação Avançada (ainda vou complementar)}

Em todos os tratamentos foram utilizados $\mathrm{H}_{2} \mathrm{O}_{2}\left(35 \%\right.$ w/w) e para o Fenton o $\mathrm{FeSO}_{4} .7 \mathrm{H}_{2} \mathrm{O}$, como fonte de $\mathrm{Fe}^{2+}$. Para garantir uma total disponibilidade de espécies catalíticas ativas, o efluente teve seu $\mathrm{pH}$ reduzido a 3 com o objetivo de evitar a sua inativação na forma de $\mathrm{Fe}(\mathrm{OH})_{2}$. Para ajuste de $\mathrm{pH}$, soluções $1 \mathrm{M}$ de ácido sulfúrico e hidróxido de sódio foram adicionadas, conforme o caso. A concentração de peróxido de hidrogênio seguiu a relação:

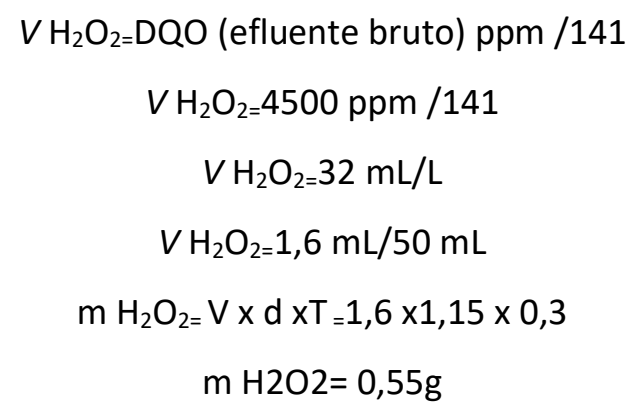

A massa usada do sulfato ferroso hepta-hidratado seguiu as relações da tabela 4. Os experimentos foram conduzidos à temperatura ambiente $\left(2^{\circ}{ }^{\circ} \mathrm{C}\right)$ segundo o fluxograma da figura 2.

Tabela4: Relação $\mathrm{FeSO}_{4} .7 \mathrm{H}_{2} \mathrm{O} / \mathrm{H}_{2} \mathrm{O}_{2}$.

\begin{tabular}{l|l|l|l}
\hline Tratamento & $\mathrm{FeSO}_{\mathbf{4}} \mathbf{7} \mathbf{H}_{\mathbf{2}} \mathbf{O} / \mathbf{H}_{\mathbf{2}} \mathbf{O}_{\mathbf{2}}$ & $\mathrm{FeSO} \mathbf{O}_{\mathbf{.}} \mathbf{7} \mathbf{H}_{\mathbf{2}} \mathbf{O}$ & $\mathbf{H}_{\mathbf{2}} \mathbf{O}_{2}(\mathbf{g})$ \\
\hline $\mathrm{TPOA}_{0}$ & $0 / 0$ & 0 & 0 \\
\hline $\mathrm{TPOA}_{1}$ & $0 / 1$ & 0 & 0,55 \\
\hline $\mathrm{TPOA}_{2}$ & $1 / 1$ & 0,55 & 0,55 \\
\hline $\mathrm{TPOA}_{3}$ & $1 / 2$ & 0,55 & 1,10 \\
\hline $\mathrm{TPOA}_{4}$ & $1 / 4$ & 0,55 & 2,2 \\
\hline $\mathrm{TPOA}_{5}$ & $1 / 6$ & 0,55 & 3,3 \\
\hline
\end{tabular}




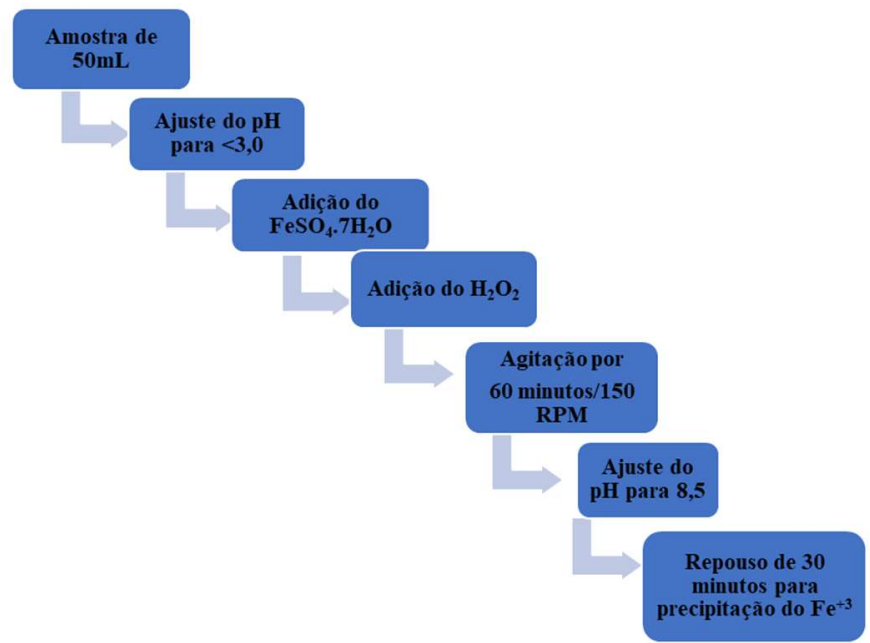

Figura 2: Fluxograma do tratamento com Fenton.

\section{Tratamento Estatístico}

As análises dos dados foram realizadas no software $R^{\circledast}$ 4.0.2 utilizando-se dos pacotes e suas bibliotecas library (ggplot2), library (dplyr), library (psych), library (readx1), library (corrplot). Antes da execução dos testes foi testada a normalidade dos tratamentos pelo teste/método de Shapiro-Wilk, nível de confiança de $95 \%(\alpha=0,05)$. Os testes executados foram paramétricos e não-paramétricos sendo os paramétricos a regressão linear bivariada, correlação de Pearson (Pearson's bivariate product-moment correlation) e o modelo não paramétrico utilizado foi o boxplot e a correlação bivariada de Kendall (Kendall's rank bivariate correlation $\tau$ ). Além desses testes a estatística descritiva foi realizada.

\section{RESULTADOS E DISCUSSÃO}

\section{Caracterização do efluente}

O efluente em questão, por estar relacionado com a tinturaria, possui diferentes classes de químicos e corantes têxteis orgânicos. Com base nisso, faz-se necessário o tratamento adequado, visto que a coloração pode afetar o pH, por exemplo (HASSAN et al., 2009). O tratamento objetivou eliminar os excessos de substâncias tóxicas e inorgânicas e, acima de tudo, o enquadramento aos padrões legais de lançamento de efluentes no corpo receptor, fator importante, como citado por Rocha et al. (2016). Na Tabela 5 são apresentadas a caracterização físico-químicas do efluente bruto empregado nos ensaios de coagulação/floculação, adsorção e oxidação avançada. O efluente antes de ser submetido aos tratamentos encontrava-se na faixa de neutralidade $(7,20)$. Autores como Silva et al. (2019) obteve um efluente têxtil bruto com o pH próximo ao mencionado, sendo 7,47, e Ntulli et al. (2009) encontraram valores de pH na faixa de 5,2 e 11,8. O pH influencia em diferentes tratamentos, como por exemplo na adsorção, sendo influenciada pelo grau de ionização do adsorvato, que paralelamente também é influenciada pelo Potencial Hidrogeniônico.

De forma geral, a legislação aponta que o pH ideal para não comprometer a biota aquática e para que não ocorra efeitos indiretos em diferentes espécies de animais, é o pH na faixa de 6 e 9 (CETESB, 2012). 
Com base nisso, os dados obtidos na caracterização do efluente permitiram verificar que o pH no efluente encontra-se dentro dos limites de descarte estabelecidos pela Resolução $n^{\circ}$ 430/2011 do CONAMA, que é na faixa de 5 a 9. É comum que as águas residuárias de indústrias têxteis tenham uma certa alcalinidade por conta dos compostos utilizados na fixação de corantes (PIZATO et al., 2017). Além disso, o pH 7 geralmente é dito como ideal para a aplicação do floculante nas primeiras etapas do tratamento (FORTINO et al., 2012).

Hassemer et al. (2002) realizaram um estudo com efluentes têxteis e os ensaios de coagulação e floculação. Esses autores utilizaram o sulfato de alumínio como coagulante e concluíram que, para o estudo em questão, os melhores resultados para redução da turbidez foi com o pH na faixa de 7,27 (MARQUES et al., 2017). Os parâmetros turbidez e DQO do efluente analisado apresentaram valores elevados, 169,6 e $4633,33 \mathrm{mg} / \mathrm{l}$, respectivamente, caracterizando um efluente com alta carga poluidora, e assim, necessitando de um tratamento antes do seu descarte.

Tabela 5: Parâmetros físico-químicos do efluente bruto.

\begin{tabular}{l|l}
\hline Parâmetros & Efluente Bruto \\
\hline pH & 7,20 \\
\hline Turbidez & 169,6 (UNT) \\
\hline DQO & $4633,3(\mathrm{mg} / \mathrm{L})$ \\
\hline
\end{tabular}

A Resolução CONAMA 357/05 e 430/2011 no que diz respeito a condições de lançamento de efluentes, não estabelece um limite máximo do parâmetro de turbidez. Desta forma para análise da mesma, será considerado o valor aceitável para águas doces, da Normativa Conjunta COPAM 01/2008, Capítulo IIISeção II, das Condições de Qualidade dos Ambientes Aquáticos. Nesta seção fica estabelecido turbidez até 40 UNT Já para a DQO, com base na tabela apresentada, a DQO do efluente bruto foi superior em relação aos limites estabelecidos pela CONAMA no 357/2005 para lançamentos de efluentes industriais em corpos receptores (limite de $50 \mathrm{mg.l}$-1). Em suma, quanto a turbidez e DQO, a amostra encontra-se fora dos limites permitidos e para o descarte em corpos hídricos, comprovando a necessidade de tratamento prévio antes que seja efetuado o descarte.

\section{Coagulação/Floculação}

Na Tabela 6 são apresentados os resultados do tratamento de coagulação/Floculação para os parâmetros Turbidez, DQO e pH (médias) nas respectivas dosagens do coagulante $\left(\mathrm{Al}_{2}\left(\mathrm{SO}_{4}\right)_{2}\right)$ - mg/L.

Tabela 6: Tratamentos de Coagulação/Floculação.

\begin{tabular}{|c|c|c|c|c|}
\hline \multirow{2}{*}{ Tratamento } & \multirow{2}{*}{ Dosagem de coagulante $\left(\mathrm{Al}_{2}\left(\mathrm{SO}_{4}\right)_{2}\right)-\mathrm{mg} / \mathrm{L}$} & \multicolumn{3}{|l|}{ Médias } \\
\hline & & Turbidez & DQO & $\mathrm{pH}$ \\
\hline T1CF & 15 & 43,90 & 2724,44 & 7,18 \\
\hline $\mathrm{T} 2 \mathrm{CF}$ & 20 & 41,73 & 3080,00 & 7,15 \\
\hline T3CF & 25 & 32,47 & 2761,11 & 7,08 \\
\hline T4CF & 30 & 28,07 & 1764,44 & 7,10 \\
\hline T5CF & 35 & 26,67 & 1674,44 & 7,15 \\
\hline T6CF & 40 & 31,50 & 2247,78 & 7,16 \\
\hline T7CF & 45 & 24,17 & 1434,44 & 7,05 \\
\hline T8CF & 50 & 23,20 & 1403,33 & 7,07 \\
\hline T9CF & 55 & 33,60 & 2096,67 & 7,02 \\
\hline T10CF & 60 & 33,17 & 2136,67 & 7,03 \\
\hline
\end{tabular}


Comparação da eficiência dos tratamentos físico-químicos de efluente têxtil utilizando sulfato de alumínio, carvão ativado e o processo oxidativo avançado fenton (H2O2)

SOUSA, S. S. O.; LACERDA, G. L. B.; ALBUQUERQUE, M. G.; SANTOS, P. N. F.; TAVARES, R. G.; SANTOS, S. N.; DIAS, V. B.

Para um melhor vislumbre da eficácia do tratamento de Coagulação/Floculação, à base de sulfato de alumínio, foram gerados gráficos quanto aos parâmetros de $\mathrm{pH}$, turbidez e DQO. Os Resultados foram comparados aos limites estabelecidos pela Resolução no 430 (CONAMA, 2011) e pela Norma técnica CPRH ${ }^{\circ}$ 2.001 (PERNAMBUCO, 2001).

A Resolução no 430 (CONAMA, 2011) que dispõe sobre as condições e padrões de lançamento de efluentes à nível nacional, determina que os efluentes de qualquer fonte poluidora somente poderão ser lançados diretamente no corpo receptor com faixa de $\mathrm{pH}$ entre 5 e 9 . Observando-se o pH do efluente bruto $(7,20)$, constata-se que o efluente já apresentava o valor inicial dentro do estabelecido na norma. Após os ensaios de Coagulação/Floculação o pH variou em entre 7,02 - 7,18, não diferindo significativamente do efluente bruto (Figura 3). Esses valores ficaram dentro dos limites estabelecido pela Resolução citada.

Vários autores (PAIVA, 2015; NASCIMENTO et al., 2020; SANTANA et al., 2020) enfatizam a importância do pH no controle dos processos físico-químicos de tratamentos de efluentes industriais, isso porque agentes coagulantes atuam melhor em meio alcalino. A eficiência da coagulação e da floculação é influenciada por diversos fatores como pH, turbidez, cor, dosagem do coagulante, intensidade de agitação, entres outros.

Foram medidos os valores de DQO e turbidez para cada amostra tratada em triplicata, após o tempo de sedimentação estabelecido de $20 \mathrm{~min}$. Na Figura 4 observa-se os resultados da eficiência da diminuição do DQO para os ensaios de Coagulação/Floculação.

O tratamento com sulfato de alumínio apresentou a melhor eficiência de redução de DQO na concentração de 50 ppm, sendo observado uma redução de 70\%. Já a concentração de 20 ppm apresentou a menor eficiência de 33,5\%. De acordo com a Norma técnica CPRH n² 2.001 (PERNAMBUCO, 2001), as indústrias têxteis deverão remover 80\% da carga orgânica não-biodegradável (DQO) dos efluentes. Logo, o tratamento de Coagulação/Floculação, para o efluente estudado, não é suficiente para uma remoção eficiente da DQO. A norma ainda determina que se o percentual encontrado for menor, as empresas deverão realizar mudanças no processo produtivo ou no controle de efluentes orgânicos, para adequar a DQO ao limite fixado.

Em relação ao parâmetro turbidez, todas as dosagens de sulfato de alumínio apresentaram redução superior a 70\%, os maiores valores na remoção de turbidez (86\%) foram obtidos empregando a concentração de $50 \mathrm{ppm}$. Logo, todos os tratamentos foram eficazes, com eficiência significante. A Resolução $n^{\circ} 430$ (CONAMA, 2011) não estabelece limites para parâmetro de turbidez. No presente estudo, em todas as condições testadas o parâmetro turbidez se manteve abaixo de 45 UNT.

Dotto et al. (2019) obteve uma redução de $87,6 \%$ de turbidez e 73,6\% de DQO para efluentes têxteis, utilizando o coagulante sulfato de alumínio entre uma faixa de pH 5 e 6 . Nesta pesquisa, obteve-se redução da turbidez $86 \%$ e DQO $70 \%$ de eficiência, respectivamente, utilizando-se Sulfato de Alumínio com pH entre $7,02-7,18$ 


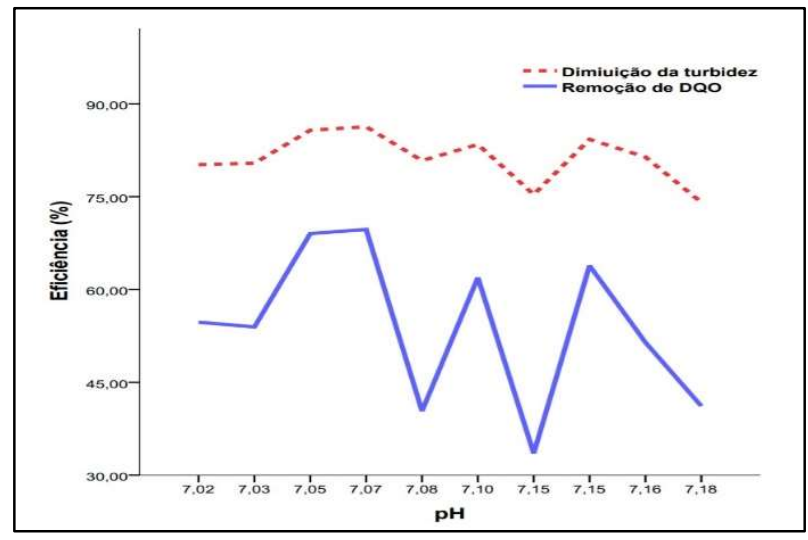

Figura 3: Variação do $\mathrm{pH}$ frente aos tratamentos de Coagulação/Floculação.

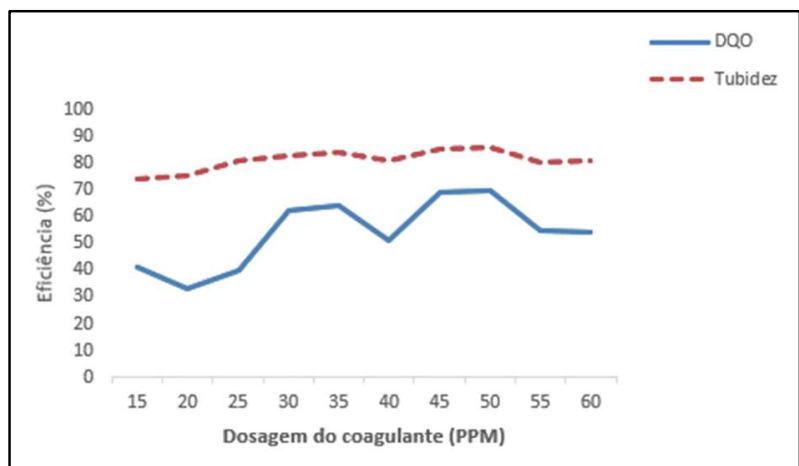

Figura 4: Eficiência da remoção de DQO e Turbidez do efluente com as concentrações do coagulante (PPM).

Marques et al. (2017) também estudaram a aplicação do coagulante sulfato de alumínio no tratamento de efluente de indústria têxtil e obtiveram uma remoção de $96,84 \%$ para turbidez e 58,9\% para DQO, nas condições de $450 \mathrm{mg} / \mathrm{L}$ de coagulante, pH ajustado para 6 e 50 min de sedimentação. Já Souza et al. (2016) realizou testes de coagulação/floculação em efluente têxtil utilizando três coagulantes: Sulfato de Alumínio, Tanino Vegetal e Policloreto de Alumínio (PAC). Os autores, após determinarem as dosagens dos coagulantes e o valor do $\mathrm{pH}$, realizaram testes para determinação da eficiência do tratamento. $\mathrm{O}$ coagulante sulfato de alumínio apresentou redução de $77,14 \%$ da turbidez e 53,49\% de DQO.

Vê-se que Marques et al. (2017) utilizou maiores dosagens de sulfato de alumino e um tempo de sedimentação superior comparado ao utilizado no presente estudo que foram, respectivamente, 50 ppm (melhor eficiência) e tempo de sedimentação de 20 min. O referido Autor obteve uma melhor remoção de turbidez $(96,84 \%)$, por outro lado, nessa pesquisa obteve-se melhor redução de DQO (70\%). A Tabela 7 resume os resultados de remoção de DQO e Turbidez obtidos pelos citados autores, no tratamento de efluentes de têxteis a partir do processo de Coagulação/Floculação.

Tabela 7: Comparação de Remoção de DQO e Turbidez de outros estudos.

\begin{tabular}{l|l|l|l}
\hline Processo & Remoção DQO & Remoção Turbidez & Fonte \\
\hline Coagulação/Floculação & $73,6 \%$ & $87,6 \%$ & Dotto et al. (2019) \\
\hline Coagulação/Floculação & $58,9 \%$ & $96,84 \%$ & Marques et al. (2017) \\
\hline Coagulação/Floculação & $53,49 \%$ & $77,14 \%$ & Souza et al (2016) \\
\hline
\end{tabular}

Os valores de remoção de DQO da presente pesquisa de $70 \%$ para os processos de Coagulação/Floculação, são superiores aos trabalhos de Marques et al. (2017) e Souza et al. (2016). No caso da remoção de Turbidez (86\%), esse estudo apresentou resultados melhores do que Souza et al (2016). 0 estudo de Dotto et al. (2019), apresentou melhores resultados na remoção de DQO $(73,6 \%)$ comparado com os demais. Já Marques et al. (2017) apresentou a melhor remoção de Turbidez (96,84\%).

\section{Ensaios de Adsorção}

\section{Determinação do Ponto de Carga Zero (PCZ)}

$\mathrm{O}$ carvão ativado foi usado para remoção de corantes reativos. $\mathrm{O}$ valor do $\mathrm{pH}_{\mathrm{pcz}}$ para esse carvão foi 
7,2 e os valores do pH medidos no equilíbrio para os corantes reativos foram 5,0, 7,2 e 8,5. Baixos valores de $\mathrm{pH}$ indicam fortemente que o carvão ativado F-400 tem carga positiva na camada externa (no equilíbrio pH) durante o processo de adsorção. Essas cargas positivas atacam as porções negativas dos corantes reativos (VASQUES et al., 2011).

\section{Teste de Adsorção}

Para o parâmetro turbidez, a eficiência na diminuição variou entre 3 e 68\% (Figura 7). Esses valores de mínima remoção são comumente evidenciados na fase de neutralização, onde não se atinge os patamares de desestabilização do meio, de forma suficiente, a favorecer o processo de adsorção. No entanto, quando ocorre a suspensão da fase de neutralização (ou seja, consumo dos íons H+ para conjugação com fontes básicas), existe um excesso de íons $\mathrm{H+}$, favorecendo a eficiência de remoção.

Valores intermediários de eficiência de remoção entre 60 e $68 \%$ foram encontrados nos tratamentos ADS1, ADS2, ADS3 e ADS4, com adição de carvão ativado nas concentrações de 0,2 g/L, 0,4 g/L, 0,6 g/L e 0,8 $\mathrm{g} / \mathrm{L}$, respectivamente. Observa-se que com o aumento da concentração do adsorvente (acima de 0,8 g/L), a eficiência do tratamento reduz bruscamente. Para Metcalf et al. (2016), a inibição do processo de adsorção devido à competição entre os compostos presentes, ocasionando redução na eficiência, pode estar relacionada ao tamanho das moléculas que estão sendo adsorvidas, à sua afinidade com o adsorvente e sua concentração relativa.

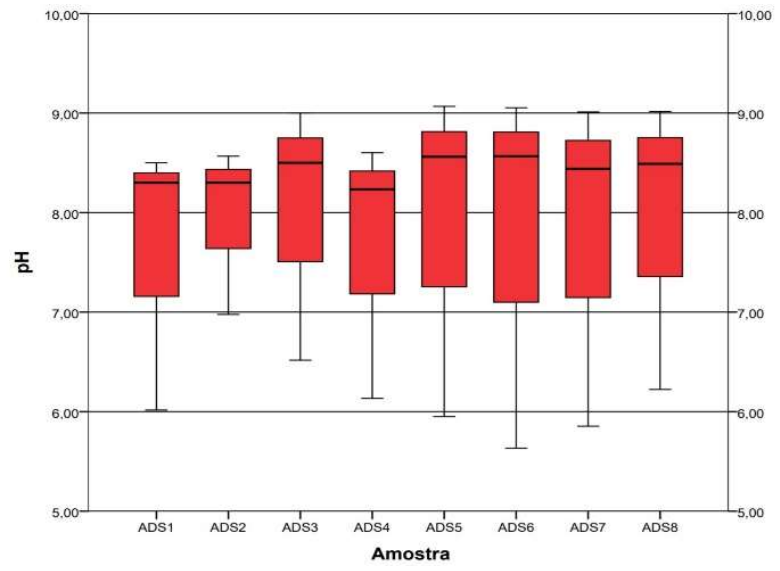

Figura 6: Variação do pH no tratamento de adsorção utilizando carvão ativado.

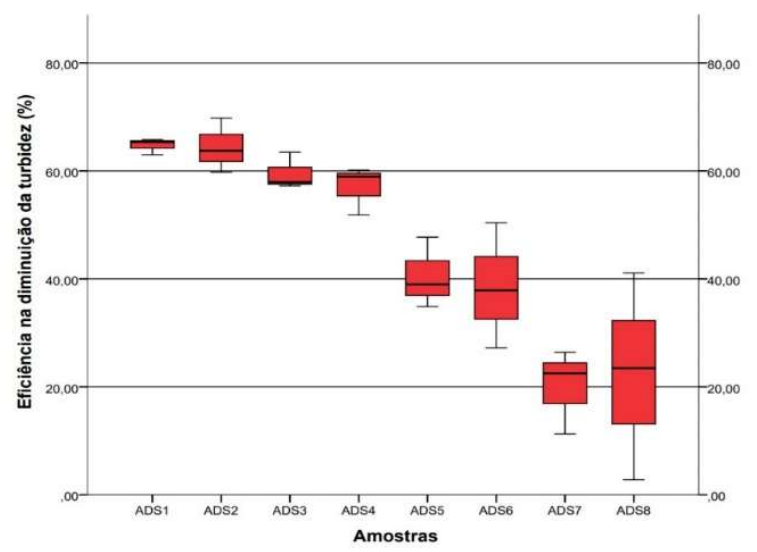

Figura 7: Eficiência de remoção da turbidez do efluente por adsorção.

Na Figura 8 podem ser observados os resultados da eficiência da redução da DQO para os tratamentos por adsorção utilizando carvão ativado. No que se refere a eficiência de remoção do parâmetro da DQO, houve uma variação entre 75,5 e 89,9\%, apresentando valores de eficiência superiores a $85 \%$ para sete dos oito tratamentos realizados.

Na condição de pH 5,5, o adsorvente apresenta as duas maiores eficiências médias de remoção de DQO (89,9 e 88,5\%), utilizando-se concentrações de 8 e 0,2 g/l de carvão ativado (Figura 9). Para o parâmetro turbidez na condição de pH 5,5, o adsorvente apresenta uma maior capacidade de adsorção (69,8\%), utilizando-se uma concentração de $0,4 \mathrm{~g} / \mathrm{L}$ de carvão ativado. Vale destacar a predominância do pH 5,5 na 
eficiência média de remoção dos parâmetros de DQO e turbidez em todos os tratamentos.

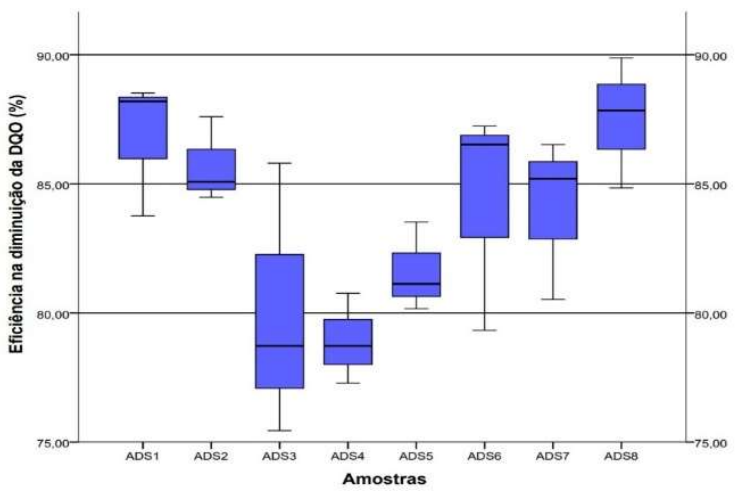

Figura 8: Eficiência de remoção da DQO do efluente por adsorção.

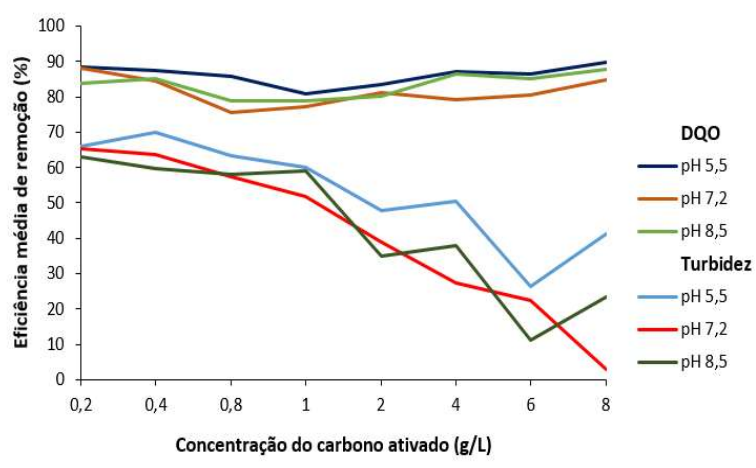

Figura 9: Relação entre a eficiência média de remoção dos parâmetros e a concentração de adsorvente nos diferentes valores iniciais de $\mathrm{pH}$.

$\mathrm{O}$ pH é um fator que influi na capacidade de adsorção do adsorvente devido à sua influência sobre as características de superfície do adsorvente. Outro fator de importância é o ponto de carga zero ( $\mathrm{pH}$ PCz), um índice conveniente da tendência de uma superfície se tornar positiva ou negativamente carregada em função do pH é o valor de pH requerido para que a carga líquida do adsorvente seja nula. Para valores de pH inferiores ao (pHzpc), a carga superficial é positiva e a adsorção de ânions é favorecida, e para valores de pH superiores ao (pHzpc) a carga superficial é negativa e a adsorção de cátions é favorecida (GOMES et al., 2017).

\section{O Uso do Fenton/ $\mathrm{H}_{2} \mathrm{O}_{2}$ para Tratamento do Efluente Têxtil}

No tratamento do efluente pelo uso do Fenton $/ \mathrm{H}_{2} \mathrm{O}_{2}$, foram aplicados cinco testes com diferentes concentração nas relações de $\mathrm{FeSO}_{4} \cdot 7 \mathrm{H}_{2} \mathrm{O} / \mathrm{H}_{2} \mathrm{O}_{2}$. Antes da inserção dos reagentes, o efluente foi ajustado para o $\mathrm{pH}$ próximo do $\mathrm{pH}=3$ a fim de propiciar a formação de íons férricos.

Ao final do experimento, a DQO apresentou o comportando apresentado na Figura 10 onde a remoção da DQO variou aumentando a eficiência de remoção ao passo que se aumentava a quantidade de reagentes inseridos. Observou-se uma maior eficiência de remoção em $96 \%$ na relação dose (Sulfato ferroso/Peróxido de Hidrogênio) de 0,55: 2,2. Ao aumentar a quantidade de Sulfato ferroso/Peróxido de Hidrogênio, observou-se um decaimento da eficiência da remoção da DQO. Este comportamento ocorre devido ao excesso de $\mathrm{H}_{2} \mathrm{O}_{2}$, onde ao final do tratamento as moléculas dissociadas que não se ligaram a moléculas do corante associam-se novamente e formam o peróxido. Corroborando com os resultados obtidos, Valverde et al. (2015) constatou que após o processo Fenton houve a redução de 99,77\% da DQO.

Ao analisar o comportamento da remoção de DQO e Turbidez (Figura 10), pode-se observar que no primeiro ponto da relação de dosagem sulfato ferrosos/peróxido, onde há apenas inserção do Peróxido de Hidrogênio (H2O2), a eficiência do sistema é baixa, representando 32\%. À medida que o Sulfato ferroso $\left(\mathrm{Fe}^{2}+\right)$ é inserido em diferentes dosagens, verificou-se a elevação da eficiência na remoção de DQO e diminuição da turbidez.

Em se tratando do pH final após a inserção dos reagentes (Figura 11), observou-se que ao final da 
reação em todas as amostras o pH tornou-se alcalino, dentro da faixa de $\mathrm{pH} 8,5$ a 8,92. A amostra POA4, que apresentou a melhor eficiência, obteve-se um pH final mais alcalino que as demais. Porém, no que diz respeito amostra POA2, obteve-se um valor menor de 8,5, abaixo do valor resultado da amostra POA1 de 8,9 na qual foi inserido a menor dosagem de reagente Fenton. Neste trabalho, observa-se que não há padrão da variação de $\mathrm{pH}$ relacionado com a dosagem de reagente, porém há a tendência na alcalinidade.

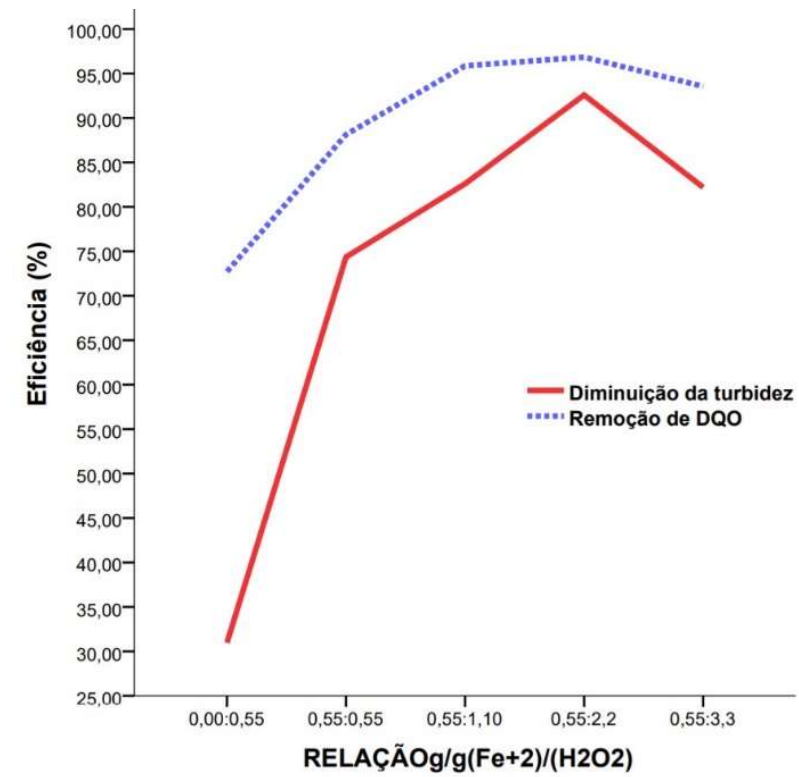

Figura 10: Relação dose-resposta-dos reagentes a remoção da DQO e diminuição da Turbidez.

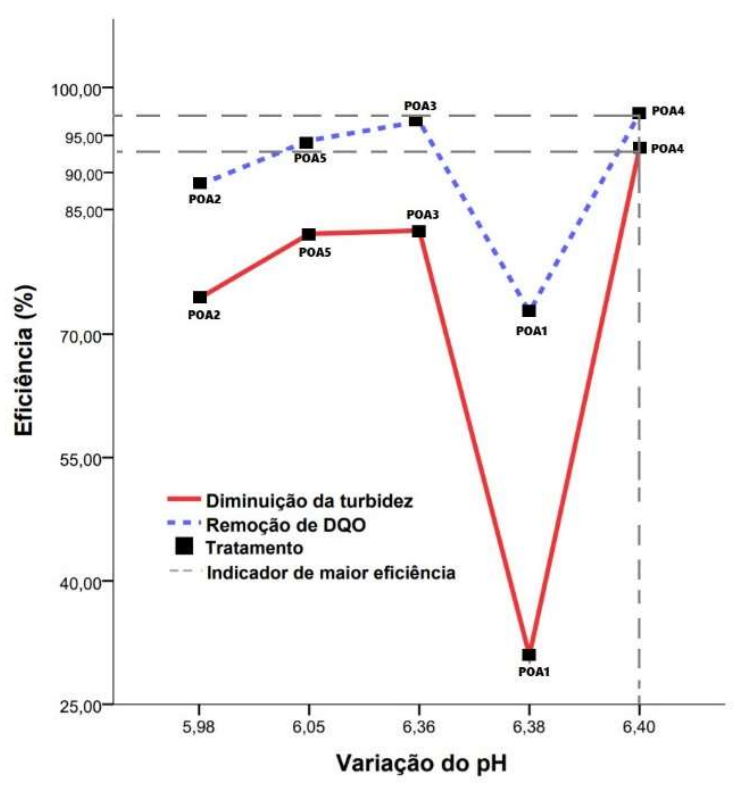

Figura 11: Variação do $\mathrm{pH}$ frente a remoção da DQO e diminuição da Turbidez.

\section{Análise Estatística}

\section{Teste de Normalidade dos Resíduos}

A primeira análise de resíduos é o teste de normalidade. O resultado do teste estatístico ShapiroWilk foi obtido a partir do software $R^{\circledR}$ 4.0.2. Para as análises de coagulação/floculação e de $P O A$ Fenton $/ \mathrm{H}_{2} \mathrm{O}_{2}$, o primeiro experimento consistiu de dez tratamentos, o segundo experimento apresentou oito tratamentos, e o terceiro dez tratamentos. Os resultados foram submetidos aos testes de normalidade e homogeneidade, seguindo o modelo de Shapiro Wilk.

\section{CONCLUSÕES}

A combinação dos três processos de tratamentos (coagulação, adsorção e POA), utilizando o sulfato de alumínio como coagulante, o carvão ativado como adsorvente e para o POA o sulfato ferroso /peróxido de hidrogênio, alcançaram altas relações nos parâmetros. Com as características observadas no efluente, conclui-se que este pode ser despejado por ter valores ideias de eficiência para tratamento de efluente.

Para a coagulação utilizou-se o sulfato de alumínio, na concentração de 50 ppm observou-se uma eficiência de 70\% para remoção de DQO, o que de acordo com a Norma Técnica CPRH n 2.001 não é permissível. Para a remoção de turbidez, a remoção foi de $86 \%$, sendo assim, eficiente. Para a adsorção utilizou-se o carvão ativado com uma condição de pH 5,5. Mostrou a eficiência de redução de DQO alta de 
$89 \%$ e para redução de turbidez $69,8 \%$. No tratamento POA houve uma redução de $96 \%$ da DQO e redução da Turbidez, se mostrando um tratamento de alta eficiência.

Avaliando os três processos pode se chegar a uma conclusão que a coagulação, adsorção e POA atingiram boas eficiências de remoção de poluentes. Porém, o tratamento por Processo Oxidativo Avançando apresentou maior eficiência. Portanto, pode-se constatar que esta é uma tecnologia promissora para tratamento de efluentes.

\section{REFERÊNCIAS}

ARAÚJO, K. S.; ANTONELLI, R.; GAYDECZKA, B.; GRANATO, A. C.; MALPASS, G. R. P.. Processos oxidativos avançados: uma revisão de fundamentos e aplicações no tratamento de águas residuais urbanas e efluentes industriais. Rev. Ambient. Água, v.11, n.2, p.387-401, 2016.

BELTRAME, T. F. BELTRAME, A. F.; LHAMBY, A. R.; PIRES, V. K.. Efluentes, resíduos sólidos e educação ambiental: Uma discussão sobre o tema. Revista Eletrônica em Gestão, Educação e Tecnologia Ambiental, v.20, n.1, p.283-294, 2016.

CONAMA. Resolução Conama $\mathbf{n}^{\circ}$ 357, de 17 de março de 2005. Dispõe sobre a classificação dos corpos de água e diretrizes ambientais para o seu enquadramento, bem como estabelece as condições e padrões de lançamento de efluentes, e dá outras providências. Brasília: CONAMA, 2005.

CONAMA. Resolução Conama $\mathbf{n}^{\circ}$. 430, de 13 de maio de 2011. Dispõe sobre as condições e padrões de lançamento de efluentes, complementa e altera a Resolução $n^{\circ}$. 357, de 17 de março de 2005, do Conselho Nacional do Meio Ambiente. Brasília: CONAMA, 2011.

COPAM. Conselho de Política Ambiental. Normativa Conjunta COPAM/CERH-MG no 01, de 05 de maio de 2008. Dispõe sobre a classificação dos corpos de água e diretrizes ambientais para o seu enquadramento, bem como estabelece as condições e padrões de lançamento de efluentes, e dá outras providências. Belo Horizonte: COPAM, 2008.

CETESB. Companhia, de Tecnologia de Saneamento Ambiental. Variáveis de qualidade das águas. São Paulo: CETESB, 2007.

CUNHA, A. L. X.; PEREIRA NETO, L. M.; ARRUDA, V. C. M.; SILVA, V. P.; CUNHA FILHO, M.; TAVARE, R. G.. Tratamento físico-químicos de efluente têxtil utilizando sulfato de alumínio, carvão ativado e Moringa Oleífera (Moringa moringa (L.) Revista GEAMA, v.5, n.3, p.47-55, 2019.

DOTTO, J.; FAGUNDES-KLEN, M. R.; VAIT, M. T.; PALÁCIO, S. M.; BERGAMASCO, R.. Performance of different coagulants in the coagulation/flocculation process of textile wastewater. Jornal of Cleaner Production, v.208, p.656-665, 2019.

FORTINO, P. C.. Pós-tratamento de efluente têxtil usando coagulação/floculação combinado com processos de separação por membranas. Dissertação (Mestrado em engenharia química) - Universidade Federal do Rio Grande do Sul, Porto Alegre, 2012.

FRANCO, C. S.; BATISTA, M. D. A.; OLIVEIRA, L. F. C.; KOHN, G. P.; FIA, R.. Coagulação com semente de moringa oleifera preparada por diferentes métodos em águas com turbidez de 20 a 100 UNT. Engenharia Sanitária e Ambiental, Rio de Janeiro, v.22, n.4, 2017. DOI: https://doi.org/10.1590/s1413$\underline{14522017145729}$

GOMES, V. C.; SILVA, B. M.; PASCHOALATO, C. F. P. R.; PISANI JÚNIOR, R.. Influência de dureza e pH na capacidade adsortiva de diuron em carvão ativado. Revista DAE, v.65, n.208, p.21-34, 2017. DOI: http://doi.org/10.4322/dae.2017.003

HASSAN, M. A. A.; LI, T. P.; NORR, Z. Z.. Coagulation and flocculation treatment of wastewater in textile industry using chitosan. Journal of Chemical and Natural Resources Engineering, v.4, n.1, p.43-53, 2009.

HASSEMER, M. E. N.; SENS, M. L.. Tratamento do efluente de uma indústria têxtil: processo físico-químico com ozônio e coagulação/floculação. Engenharia Sanitária e Ambiental, Rio de Janeiro, v.7, n.1, p.30-36, 2002.

LATIF, U.; DICKERT, F. L.. Graphene Hybrid Materials in Gas Sensing Applications. Sensors, n.15, p.30504-30524, 2015.

LUTOSA, G. M. M. M.; MOITA NETO, J. M.; SILVA, C. E.. Degradação de efluente têxtil pela reação de fenton. Revista Virtual de Química, v.5, n.5, p.973-980, 2013.

MARQUES, M. P.; ARAÚJO, N. S.; GOMES, P. F.; RUGGERI JÚNIOR, H. C.. Avaliação da eficiência do tratamento do efluente de uma estamparia por coagulação química. REEC Revista Eletrônica de Engenharia Civil, v.20, n.10, p.1-16, 2017.

METCALF, L.; EDDY, H. P.. Tratamento de efluentes e recuperação de recursos. 5. ed. Brasília: McGraw Hill, 2016.

MOLINOS-SENANTE, M.; GÓMEZ, T.; CABALLERO, R.; HERNÁNDEZ-SANCHO, F.; SALA-GARRIDO, R.. Assessment of wastewater treatment alternatives for small communities: An analytic network process approach. Sci. Total Environ., v.532, p.676-687, 2015.

NASCIMENTO, I. G.; RESENDE, F. M.. Estudo comparativo do uso de coagulante à base de sementes de Moringa oleifera Lam. e sulfato de alumínio no tratamento físico e químico de efluente de laticínio. Rev. Bras. Gest. Amb. Sustent., v.7, n.15, p.97-109, 2020. 
NTULLI, F.; IKHU-OBOREGBE, D.; KUIPA, P. K.; MUZENDA, E.; BELAID, M.. Characterization of effluent from textile wet finishing operations. In: WORLD CONGRESS ON ENGINEERING AND COMPUTER SCIENCE, SAN FRANCISCO. Anais. 2009. p.69-74.

PAIVA, T. M. N.. Estudo de remoção de corantes aniônicos em conchas de molusco bivalves. Tese (Doutorado em Engenharia Química) - Universidade Federal de Pernambuco, Recife, 2015.

PERNAMBUCO. Agência Estadual de Meio Ambiente (CPRH). Norma Técnica $n^{\circ}$ 2.001. Controle de carga orgânica em efluentes líquidos industriais - estabelece critérios e padrões de emissão que resultem na redução da carga industrial lançada direta ou indiretamente nos recursos hídricos do estado de Pernambuco. Recife: CPRH, 2001.

PIZATO, E.; LOPES, A. C.; ROCHA, R. Q. C.; BARBOSA, A. M.; CUNHA, M. A. A.. Caracterização de efluente têxtil e avaliação da capacidade de remoção de cor utilizando o fungo Lasiodiplodia theobromae MMPI. Engenharia Sanitaria e Ambiental, v.22, n.5, p.1027-1035, 2017. DOI: https://doi.org/10.1590/s1413-41522017121743

QUEIROZ, M. T. A.; QUEIROZ, C. A.; ALVIM, L. B.; SABARÁ, M. G.; LEÃO, M. M. D.; AMORIM, C. C.. Reestruturação na forma do tratamento de efluentes têxteis: uma proposta embasada em fundamentos teóricos. Gestão \& Produção, v.26, n.1, 2019.

QUEIROZ, M. T. A.; LIMA, L. R. P.; ALVIM, L. B.; LEÃO, M. M. D.; AMORIM, C. C.. Gestão de resíduos na indústria têxtil e sua relação com a qualidade da água: estudo de caso. Iberoamerican Journal of Industrial Engineering, v.8, n.15, p.114-135, 2016

ROCHA, G. F.; LIMA, S. M.; SANTOS, M. S. F.. Análise do reaproveitamento da água no processo produtivo em uma lavanderia têxtil da cidade de Teresina. In: ENCONTRO NACIONAL DE ENGENHARIA DE PRODUÇÃO. Anais. João
Pessoa: Centro de Convenções, 2016.

SANTANA, G. B.; NÓBREGA, D. C.; OLIVEIRA, J. T.; MARTINS, I. A.; NASCIMENTO, R. F.; VIDAL, C. B.. Aplicação da semente de moringa (Moringa oleífera) como coagulante natural no tratamento de efluente de indústria de tintas no Ceará. Revista Tecnologia, v.41, n.1, p.1-17, 2020.

SILVA, L. D.; DANTAS, P. R.; PEREIRA NETO, L. M.; ARRUDA, V. C. M.; TAVARES, R. G.; SILVA, V. P.. Eficiência da coagulação, floculação e decantação como tratamento primário de efluente têxtil. Revista Geama, v.5, n.1, p.36-40, 2019.

SOUZA, P. C.; PEREIRA, N. C.; GONÇALVES, M. S.; FILHO, N. S.; RODRIGUES, P. H.; JAMARIM, V. M.. Estudo do tratamento de efluente têxtil através de processos de coagulação/floculação e eletrocoagulação. Revista E-Xacta, Belo Horizonte, v.9, n.2, p.123-132, 2016.

STOPPE, A. C. R.; FAIAD, J. C.; CUNHA, L. M. P.; SANTOS, K. G.; VIEIRA NETO, J. L.. Remoção do Corante Azul de Metileno no Tratamento de Efluentes por Adsorção em Carvão de Coco Verde e Carvão Ativado. In: CONGRESSO BRASILEIRO DE SISTEMAS PARTICULADOS, ENEMP, 39. Anais. 2019.

VALVERDE, R. P.; MORAIS, A. C. M.; CAIXETA, L. R.; CARNEIRO, G. T.. Viabilidade no tratamento de efluente industrial através da utilização de reagente de fenton e fotocatálise heterogêna. Revista Eletrônica de Engenharia Civil, v.11, n.1, p.35-45, 2015. DOI: https://doi.org/10.5216/reec.V11i1.34861

VASQUES, A. R.; SOUZA, S. M. A. G. U.; WEISSENBERG, L.; SOUZA, A. A. U.; VALLE, J. A. B.. Adsorção dos corantes RO16, RR2 e RR141 utilizando lodo residual da indústria têxtil. Eng. Sanit. Ambient, v.16, n.3, p.245-252, 2011.

VON SPERLING, M.. Introdução à Qualidade da Água e ao Tratamento de Esgoto, Princípio do Tratamento Biológico de Águas Residuárias. 4 ed. Belo Horizonte, 2014.

A CBPC - Companhia Brasileira de Produção Científica (CNPJ: 11.221.422/0001-03) detém os direitos materiais desta publicação. Os direitos referem-se à publicação do trabalho em qualquer parte do mundo, incluindo os direitos às renovações, expansões e disseminações da contribuição, bem como outros direitos subsidiários. Todos os trabalhos publicados eletronicamente poderão posteriormente ser publicados em coletâneas impressas sob coordenação da Sustenere Publishing, da Companhia Brasileira de Produção Científica e seus parceiros autorizados. Os (as) autores (as) preservam os direitos autorais, mas não têm permissão para a publicação da contribuição em outro meio, impresso ou digital, em português ou em tradução. 